\title{
LA DEMOCRACIA ESCRUTADA EN LAS PAILAS ELECTORALES: ALGUNAS REFLEXIONES SOCIOPOLÍTICAS DEL ÚLTIMO PROCESO ELECTORAL EN COSTA RICA Y SUS DERIVACIONES INMEDIATAS
}

\author{
THE STRUCTURED DEMOCRACY IN THE ELECTORAL PAILS: \\ SOME SOCIOPOLITICAL REFLECTION OF THE LAST ELECTORAL \\ PROCESS IN COSTA RICA AND THEIR IMMEDIATE DERIVATIONS
}

\author{
José Carlos Chinchilla Coto*
}

\section{RESUMEN}

\begin{abstract}
En este artículo se exponen los resultados del seguimiento de la coyuntura política que condujo a la elección de la primera presidenta de la República de Costa Rica. Partiendo de una recuperación analítica de los principales momentos que constituyen el conjunto total del proceso electoral de 2010, se pretende integralmente ordenar una secuencia interactiva de fenómenos y actores que permitan comprender desde una perspectiva sociopolítica el entramado, los escenarios, los actores y libretos, que se vivió recientemente en el drama político electoral y vive en sus consecuencias la democracia restringida costarricense.
\end{abstract}

PALABRAS CLAVE: COSTA RICA * ELECCIONES * DEMOCRACIA * PARTIDOS POLÍTICOS * OPINIÓN PÚBLICA

\section{ABSTRACT}

This article presents the results of the monitoring the political conjuncture that led to the election of the first woman president of the Costa Rican republic. Starting from an analytical recuperation of the main events that establish the total set of the 2010 electoral process, the aim is to integrally order an interactive sequence of actors and phenomenon that would allow understanding from a sociopolitical perspective of lattice, scenarios, the actors and librettos that in the political electoral drama we recently experienced, and nowadays live in its consequences the restricted Costa Rican democracy.

KEY WORDS: COSTA RICA * ELECTIONS * DEMOCRACY * POLITICAL PARTIES * PUBLIC OPINION 


\section{PRESENTACIÓN}

En este artículo se expone el seguimiento de la coyuntura política que condujo a la elección de la primera presidenta de la República de Costa Rica. Para ello presentamos una narración que describe la secuencia de los hechos más relevantes acontecidos en el proceso electoral 2010; así como, las estrategias utilizadas por los principales partidos políticos $y$ sus dirigentes. Por tanto, definimos cuatro momentos expositivos:

1. El primero refiere a lo acontecido en los procesos previos a las candidaturas oficiales; es decir, haremos una interpretación de las elecciones primarias del Partido Liberación Nacional (PLN) y del Partido Acción Ciudadana (PAC); así como, de lo acontecido en el Movimiento Libertario (ML) y en el Partido Unión Social Cristiana (PUSC); considerando los otros partidos minoritarios y sus roles. Todo lo anterior previamente contextualizado de manera puntual en la atmósfera política vigente.

2. Un segundo momento, describe la campaña presidencial, los temas centrales de discusión, las características que asumió la contienda y cómo se desempeñaron los actores y actrices con sus partidos en la confrontación política electoral.

3. Un tercer momento, describe los días previos de las elecciones $y$ sus resultados electorales.

4. El cuarto momento, pretende identificar algunas de las derivaciones inmediatas del resultado electoral en los distintos partidos $y$ en el gobierno emergente.

En resumen el trabajo pretende lograr una exposición sociológica, condensada y explicativa del último proceso electoral presidencial en Costa Rica.

I momento: El proceso electoral que se definió el pasado 4 de febrero de 2010 , donde por primera vez dio como resultado la elección de una mujer como presidenta de la República de Costa Rica, merece una reflexión sociopolítica, no solo porque dicho proceso - visto cuatro años antes- hubiese sido profetizado con otro resultado; sino también porque pocos meses antes de la apertura efectiva de la campaña (no oficial por el Tribunal Supremo de Elecciones-TSE) se suponía que quien tendría la representación del Partido Liberación Nacional sería otra persona diferente a la que finalmente ganó las elecciones.

Por otra parte, las grandes diferencias en los resultados electorales; así como el mayor protagonismo de la candidata sobre el partido, visto a la luz de los resultados de los y las diputadas a la Asamblea Legislativa, merecen una lectura de las tribunas sociopolíticas. En este sentido es que realizamos este esfuerzo de síntesis explicativa del proceso electoral para la presidencia 2010-2014.

\section{PROLEGÓMENOS Y FUERZAS POLÍTICAS}

El escenario político en el cual se inició la campaña para la presidencia tiene una serie de aspectos relativos a las condiciones previas que son insoslayables de abordar, ya que recogen elementos explicativos muy valiosos para comprender algunos de los resultados finales de la contienda; entre ellos haremos referencia puntual a los siguientes:

a. Las elecciones del 2006-2010 y los liderazgos políticos

b. La confrontación nacional e internacional por el TLC en Costa Rica y sus repercusiones en la política local

c. La reconfiguración de las fuerzas en un espectro amorfo

\section{LAS ELECCIONES DEL 2006-2010 Y LOS LIDERAZGOS POLÍTICOS}

El resultado de las elecciones expresó de manera incuestionable que una parte significativa de la sociedad costarricense estaba en disposición de generar un cambio significativo y aunque no radical, sí importante en la determinación de quienes debían conducir el gobierno; 
nos referimos, independientemente al hecho, de que el candidato de Liberación Nacional para esa elección fue el premio Nobel de la Paz, Oscar Arias Sánchez, su victoria fue dilatada (tuvo que esperar un conteo pormenorizado de los votos ya que no había claridad de su eventual victoria) y pírrica; ya que no alcanzó porcentajes mayores al $2 \%$ de ventaja sobre su oponente principal, Ottón Solís, candidato por el Partido Acción Ciudadana.

Para nosotros, el resultado expresaba que la ciudadanía estaba cobrándole a la clase política tradicional, su inescrupulosa actitud de participar en procesos de corrupción al más alto nivel: dos ex presidentes de la República, Rafael Ángel Calderón F. y Miguel Ángel Rodríguez estaban indiciados en los procesos de ALCATEL y del Préstamo Finlandés, respectivamente ${ }^{1}$. Aunque para ese momento no estaban juzgados, ya habían sido objeto de medidas cautelares de prisión preventiva y otras que evidenciaban a la ciudadanía los pasos turbios de ambos líderes; a los cuales se le sumaban las dudas sobre el ex presidente liberacionista José Figueres Olsen; quien se encontraba en un auto exilio por razones que eran no bien vistas por la comunidad nacional.

En este contexto de escepticismo, la ciudadanía aspiraba a un cambio y el candidato que más parecía representar el nuevo ideal de cambio para la honestidad en la gestión pública era el aspirante del Partido Acción Ciudadana, Ottón Solís. No obstante, y a pesar de las condiciones de disponibilidad para el cambio, el proceso electoral no logró materializar la visión alternativa a lo tradicional; posiblemente por problemas en el manejo táctico de la campaña y el peso de la dinámica del pasado, que siempre tiene un peso específico en un proceso electoral. Sin embargo, se logró evidenciar la posibilidad del cambio y la potencialidad de la nueva oposición.

Uno de los hechos más relevantes del proceso antes indicado, es el fracaso absoluto

1 Para una comprensión más puntual del fenómeno de la corrupción y el impacto sobre el sistema político costarricense sugerimos ver Chinchilla, José Carlos. "Corrupción y democracia en la sociedad costarricense actual.” Ponencia. ALAS: México, 2008. que tuvo el Partido Unidad Social Cristiana, el cual no logró obtener el apoyo de sus simpatizantes históricos, quienes los habían llevado al gobierno en muchas ocasiones e incluso eran gobierno para el período electoral. El electorado del Pusc se desplazó hacia Solís ${ }^{2}$ y otra parte votó nulo, o no asistió a las urnas incrementando el porcentaje de abstencionismo a más del $34 \%$. El PUSC solo obtuvo cinco diputados(as).

Lo más relevante fue que este proceso evidenció el fin del bipartidismo de una manera incuestionable, ya que se rompió con el monopolio del llamado PLUSC (Partido Liberación Nacional-Partido Unidad Social Cristiana $)^{3}$; lo que significó el surgimiento potencial de una nueva historia y nuevas exigencias en las formas de gobernar y sobre todo de obtener gobernabilidad. Recordemos que el Movimiento Libertario siendo minoritario en la Asamblea, obtuvo seis representantes que hacían más difícil la gobernabilidad y contribuían al pluralismo político, con todo y los costos de operación que conlleva para gobiernos que tienden más a concentrar autoridad que a negociar gobernabilidad.

En síntesis, estas elecciones 2006-2010 independientemente de que no estuviera gobernado el país por una nueva clase política, sí expresó un deterioro importante de la clase política tradicional $y$ de las potencialidades de fuerzas emergentes en el escenario político $y$ en las relaciones de poder político.

LA CONFRONTACIÓN NACIONAL POR EL TLC EN COSTA RICA Y SUS REPERCUSIONES EN LA POLÍTICA LOCAL

La relevancia del debate nacional sobre el Tratado de Libre Comercio entre Centroamérica, Panamá y República Dominicana con los Estados Unidos de Norteamérica (TLC) generó un fenómeno político de relevancia absoluta en el crecimiento democrático, en la transformación de las relaciones de fuerza y en la forma de

\footnotetext{
$\overline{2} \quad$ El PUSC solo obtuvo cinco espacios en el Congreso.

3 Los votos obtenidos por el PAC le posibilitaron obtener 17 escaños en la Asamblea Legislativa, lo que en contraste con el PUSC significaba el fin del bipartidismo.
} 
ejercicio del poder. En este sentido, vamos a entender que las luchas por el "Sí" y el "No" al TLC, expresan un proceso coyuntural de polarización de la ciudadanía y población costarricense; pero también es resultado, la polarización generada por los grandes cambios estructurales que a nivel sociopolítico y económico ha vivido la sociedad costarricense desde la década de los 80 y principalmente en los noventas ${ }^{4}$.

En el escenario político, ante el débil triunfo de Oscar Arias y el aparente logro de un líder de oposición consolidado: Ottón Solís, se podría haber previsto algún tipo de negociación a la vieja usanza bipartidista. Sin embargo, esto no fue posible ni siquiera intentarlo; ya que a pesar de los intereses del presidente entrante de que el tema del TLC fuera resuelto en el gobierno de Abel Pacheco (2002-2006) esto no aconteció y más bien, se planteó la necesidad de formular un proceso de Referéndum para dilucidar si se aprobaba o no el Tratado. Es importante anotar que el hecho de recurrir al Referéndum y no "resolverlo" desde la Asamblea Legislativa, expresaba el resquebrajamiento del bipartidismo y también la débil capacidad para gobernar de los Arias; en tanto no podían lograr concretar su mayor aspiración como gobierno: tener el TLC aprobado en sus primeros meses de gobierno y sobre esta base desarrollar su gestión de gobierno.

La discusión del TLC se convirtió en la discusión del Modelo de Desarrollo y el Modelo de Sociedad; es decir, por primera vez en décadas, la ciudadanía y los grupos de presión, comenzaron a argumentar y contra argumentar sus visiones de mundo y su concreción en la sociedad costarricense. Decena de debates, cientos de horas en medios radiofónicos y televisivos; así como numerosas cuartillas periodísticas llenaron los medios de comunicación de masas.

La sociedad costarricense estaba en efervescencia y la discusión enriquecía a la ciudadanía y a la población en general, empoderándola

$4 \quad$ Ver Chinchilla, J. C. "La democracia costarricense en el siglo XXI: la devaluación de los políticos tradicionales, la institucionalidad y las esperanzas democráticas". Ponencia. ACAS: El Salvador, 2008. de la discusión y con ello dando un paso adelante en la comprensión de un derecho ciudadano más allá del voto electoral; estábamos frente a un proceso sociopolítico que convocaba a una democracia participativa inédita en la historia contemporánea reciente en Costa Rica.

El gobierno tomo su posición y con todos sus recursos impulsaba el Tratado, el gabinete $y$ los diputados(as) de gobierno conformaban el Estado Mayor y el presidente su General. Por su parte, la oposición al TLC generó una situación novísima y muy amenazante para quienes tenían aparentemente la conducción de la oposición política.

Ciertamente, el resultado de las elecciones había definido en la esfera política que el líder de la oposición era Ottón Solís; pero la lucha del TLC generó un desplazamiento - por ampliación- del espacio político; donde este ya no se agotaba en los escenarios tradicionales; ahora la política invadía clara y abiertamente otros espacios de la sociedad civil y conducía a una redefinición de lo político, y la política en la cual don Ottón Solís no estaba como el único ni el "líder" de la oposición. Surgieron nuevos liderazgos y figuras que comenzaron a desplazar a Solís; sobre todo por sus tímidas posiciones y la limitada claridad con que asumió su compromiso con la lucha en contra del TLC.

En esta confrontación ideológico-política, se polarizaron más las fuerzas y grupos sociales; surgieron agrupaciones locales como los Comités Patrióticos, que no tenían una asociación o identificación partidaria y que más bien recogían inconformidades y lo que anteriormente definimos como "disponibilidad"; convirtiéndose en gestores políticos para la toma de decisiones en un espectro político más allá de los escenarios tradicionales de la política. Estábamos frente al surgimiento de nuevos actores políticos en nuevos espacios de la política, que desbordaban los ámbitos de los partidos políticos y en alguna medida fortalecían la desvalorización de los políticos tradicionales en un sector importante de la ciudadanía.

Justo o no, acertado o erróneo, casuístico o premeditado, no se le percibió a Solís como el "líder", sino que tuvo que aceptar un co-liderazgo ambiguo y difuso que terminó 
de volver escépticas a muchas personas que estaban generando oposición al TLC. En este sentido, la tesis es que parte de lo que podría explicar la gran derrota electoral del PAC y Solís se basa en lo antes expuesto. Esto se retomará más adelante.

El resultado del Referéndum en el cual el "Sí" obtuvo mayoría, no fue a nuestro juicio fruto de un convencimiento pleno de cada uno de los votantes; ya que en un acto de imperfección democrática se generó una coacción a sectores sociales trabajadores de empresas interesadas en la aprobación del TLC; así como también, se irrumpió los términos de la contienda electoral del Referéndum al interferir la veda publicitaria ordenada por el Tribunal Supremo de Elecciones. Estos hechos precedidos por un tristemente famoso "Memorándum" donde el vicepresidente Casas y el diputado Sánchez, familia de los hermanos Arias, instaban a la utilización del "miedo" para definir a favor del TLC, lo que ellos consideraban un resultado parcial negativo a la hora de emitir su convocatoria a una "campaña sucia".

La victoria electoral del "Sí", realmente no significó la entrada en vigencia del Tratado, e incluso fue casi hasta el final del gobierno de los hermanos Arias, que se terminaron de aprobar todas las leyes complementarias, requisito para la ejecución del Tratado; lo que significó un gran desgaste para el gobierno y para los partidos aliados en esa lucha; tal es el caso del PUSC y del Movimiento Libertario; aunque también para el partido opositor PAC; el cual se desgastó torpemente en esa lucha ya que centró todas sus limitadas energías en una lucha perdida. Solo el partido de Merino sacó alguna ventaja de la resistencia; aunque como se verá, ello no se tradujo en una respuesta electoral para diputados en las elecciones de febrero de 2010.

Como podemos desprender de lo anterior, la realidad política del Referéndum en la cual una serie de encuestas demostraban lo "parejo" de las intensiones de voto, hizo que por primera vez ${ }^{5}$, de una manera abierta, la clase

$5 \quad$ Nos referimos a primera vez, después de la década de los cuarenta y posterior al gobierno de los dieciocho meses del Movimiento de Liberación Nacional. política tradicional -al menos un sector de ella-y sus jóvenes allegados, estuvieran dispuestos a sobre pasar sus propias reglas y regulaciones del ejercicio democrático en función de sus objetivos y metas; ello al mejor estilo de Maquiavelo; aunque con la torpeza propia de quien ignora las fuerzas de sus oponentes.

En este contexto, el Referéndum y la polarización generada permitieron visualizar la existencia de una sociedad con dos sectores con posiciones claramente contrapuestas y más compleja aún la situación, en tanto, encontramos una polarización acompañada de indiferencia o desencanto democrático — casi en partes a licuas; en tanto, prácticamente, un tercio de quienes pueden ejercer el voto se mantienen al margen e indiferentes al ejercicio democrático de la toma de decisiones y los otros dos tercios se ubican en los extremos contrapuestos. Por lo tanto, realmente estamos frente a un país donde existen tres segmentos de población ciudadana con casi igual número de personas que tienen tres posiciones diferentes, frente al fenómeno político y ante los modelos de sociedad y desarrollo.

Con estos elementos y fenómenos políticos, el país entró en la dinámica electoral para la elección de la presidencia 2010-2014.

II momento: La reconfiguración de las fuerzas en un espectro politico amorfo en el inicio de la campaña electoral 2010-2014

Como podemos desprender de lo expuesto, la campaña se presentaba con una serie de presupuestos complejos de comprender e interrogantes difíciles de responder. Algunos de los elementos que indicaban dicha situación lo fueron:

a. Un Partido Liberación Nacional sin un claro designado(a) para la lucha electoral y con gente históricamente importante que se salía del partido, incluyendo ex ministros, ex candidatos presidenciales $y$ ex presidentes.

b. Un Partido Unidad Social Cristiana, que en medio del juicio por corrupción al ex presidente Calderón Fournier, aparecía en principio a la espera del resultado $y$ 
luego antes del mismo se declaró como candidato a Rafael Ángel Calderón; todo ello en un marco de desprestigio e incredulidad de la mayor parte de la ciudadanía y de sus propios partidarios.

c. Un Partido Acción Ciudadana, que no había logrado alzar vuelo durante cuatro años con 17 diputados(as) - luego 16para tener una base política partidaria importante; pero que además había perdido liderazgo y dominio de la oposición en la lucha por el TLC. A lo cual se le agregaba, diferencias importantes entre algunos y algunas de sus principales dirigentes; al punto que la situación obliga a realizar unas elecciones primarias para definir al candidato.

d. Un Movimiento Libertario, que inicia una campaña multimillonaria con mucho tiempo de anticipación, que logra frente al silencio del PAC apropiarse de su discurso, en cuanto a la lucha contra la corrupción y que además el ML logra "maquillar" algunas de sus posiciones anteriores; haciendo más potable su discurso ante una ciudadanía poco crítica.

e. Una serie de agrupaciones "menores" que en principio no parecía tener potencialidad para competir por más escaños legislativos, pero que tenían un discurso innovador efectivista emocionalmente -el caso del Partido Accesibilidad Sin Exclusión (PASE) - y por otra parte, grupos políticos de origen religioso (Renovación Costarricense y Restauración Nacional) con poblaciones cautivas con algún nivel de crecimiento eventual. Mención particular el surgimiento de nuevos partidos de centro izquierda y de corte nacionalista no fascista - como el liderado por el candidato liberacionista Rolando Araya (Alianza Patriótica) que busca un nicho en las personas que apoyaron el no al TLC. Por último, el Frente Amplio que aglutina sectores de la izquierda costarricense y que entraba a la contienda presidencial con uno de los líderes de la lucha contra el TLC, Eugenio Trejos, junto con dos jóvenes aspirantes a puestos en el Congreso.

f. Una población civil dividida, algunos con deseos de olvidar la política, otros con interés de restaurar la organización, o al menos la participación simpatizante del PLN y un tercer segmento, con una resaca o "goma" por el resultado del Referéndum o mejor dicho por la interpretación del resultado; que les generaba un gran escepticismo, desgano y vacío ideológico-político para inmiscuirse nuevamente en la campaña política.

Estos cinco elementos pesaban mucho en el inicio de la contienda electoral y algunos de ellos conforme se fue avanzando en el proceso electoral y perfilando; se transformaron — caso del PLN-y otros más bien profundizaron - PAC - sus contradicciones y problemas.

\section{LOS HILOS DE LA MADEJA Y EL JUEGO ELECTORAL ${ }^{6}$}

Las elecciones primarias del PLN $y$ del PAC son una de las piedras angulares explicativas del resultado final electoral; ya que las mismas cumplieron varias funciones - algunas manifiestas $y$ otras latentes - en tanto le permitió a la ciudadanía revivir mitos del pasado y enterrar los mitos del presente?

La razón es sencilla, mientras en el PLN el proceso generó confrontación y debate; así como también movilización política partidaria que permitió reconstruir e interpelar viejas y nuevas generaciones de atávicas ramificaciones verde $y$ blancas; así como demostraciones de la candidata Chinchilla de tener una capacidad amplia para

6 Como si cada partido fuera parte de una madeja que se va desenrollando, así el proceso político va tendiendo los hilos para tejer el futuro electoral; y más que un fruto del azar, se depende de la habilidad y el conocimiento e intereses que definen el punto del tejido político.

$7 \quad$ La tesis central es que en estas elecciones primarias, la lectura que hizo la opinión pública y sobre todo la ciudadanía fue que había Partido Liberación Nacional para gobernar y que el PAC era una ilusión desvanecida en las turbias y difusas aguas políticas. 
leer e interpretar los fenómenos políticos y actuar con liderazgo en consecuencia —aparentemente sin importar la supuesta hipoteca política que asumía- al aliarse públicamente con el presidente Arias. Ello ante el evidente avance que el precandidato Johnny Araya tenía en los inicios de la campaña pre electoral.

El resultado de estas elecciones primarias del PLN fue muy a favor de Laura Chinchilla; lo que permitió definir sin obstáculos el liderazgo de la candidata y su padrino, el presidente. Pero además, fue una demostración clara de la capacidad de organización y movilización del PLN; se indicó una votación cercana al medio millón; lo que en términos políticos — de ser ciertos los datos- prácticamente definía una victoria más que probable en las elecciones de febrero de 2010; siempre y cuando no ocurriera algún fenómeno extraordinario como lo fue en las elecciones anteriores, el caso de corrupción que se le imputó a los ex presidentes Rodríguez y Calderón.

Pero el asunto fue todavía más allá; ya que las elecciones primarias del PAC habían acontecido con un resultado muy pobre de participación —independientemente del carácter cerrado-y esto lo valoró la ciudadanía más de lo que se imaginaron los rojiamarillos.

Precisamente, las elecciones primarias del PAC, fueron primero que las del PLN; pero además no lograron captar una atención suficiente, dado que a pesar de tener contradicciones muy fuertes entre la precandidata Epsy Campbell y Ottón Solís; sus debates fueron tibios y dulces... quizá algo insípidos para la expectativa generada antes del mismo. Con ellos participó también un político nuevo y que brotó - como generación espontánea- de las luchas contra el TLC. Román Macaya, a quien dicha contienda le promocionó como político con potencialidad pero que no fue aprovechado posteriormente en la campaña por parte de Ottón Solís.

Votaron alrededor de veinticinco mil personas y Solís obtuvo una ratificación como candidato histórico de la agrupación ${ }^{8}$; pero fue

8 Algunas personas incluyendo dirigentes actuales del PAC, reconocen que el partido se creó para llevar a la presidencia a Ottón Solís; por lo tanto, las evidente su pérdida de liderazgo y lo que es peor, lo débil del Partido. Fue una exhibición de limitaciones político-organizacionales y de centralismo en una cúpula dirigente funcionalmente casi unipersonal.

El contraste de ambos procesos, además de los esgrimidos, se debe señalar que mientras el PAC salió dividido y con fuerzas centrípetas ${ }^{9}$ reactivadas; al punto que tanto Macaya como Campbell, estuvieron al margen de la campaña política; al menos no jugaron el papel co protagónico que se esperaba de ambos. Asimismo, con una imagen mucho menos valorada $y$ en alguna medida deteriorada. El PLN salió unitario, fortalecido, con mejor imagen que con la que inició el proceso. Se "agigantó" — diría nuestra gente-y el PAC se "empequeñeció" en el inevitable juego de los contrastes entre ambas actividades primarias y la participación obtenida.

Por su parte, el Movimiento Libertario presentó algunas contradicciones $y$ denuncias internas que al fin de cuentas fueron irrelevantes para el mediático ascenso de su también líder consuetudinario Otto Guevara; quien en esta ocasión transformó su discurso - contradiciéndose con su pensamiento anteriorhaciéndolo más potable y sencillo; partiendo del sentido común de la gente $y$ dando soluciones simplonas en las cuales nunca expuso el costo e impacto de ellas; pero casi mágicamente, y ante el vacío de un líder de oposición claro e indiscutible, pudo subir en poco tiempo como la espuma, gracias a los vacíos y al excelente financiamiento que obtuvo Guevara para su campaña.

Otto Guevara, construyó una campaña agresiva, innovadora, expropiando la idea fuerte del PAC y sobre todo, ideando placebos de respuesta a los grandes problemas nacionales. Sus intereses fueron tomando fuerza dado que

elecciones cerradas, la dinámica de las discusiones y el resultado de las mismas confirmaban estas afirmaciones.

9 Tenemos la impresión verificable, de que en el PAC se han dado desde su primera participación en la Asamblea Legislativa, fuerzas centrípetas que expulsan o distancian dirigentes que cuestionan el liderazgo gestor del partido. 
al PLN le importaba que Guevara creciera para restarle a Ottón y por otra parte, su crecimiento también por las masivas inversiones en publicidad que utilizó el candidato del ML. Otto y su partido lograron atraer a sectores sociales que posiblemente en el pasado eran simpatizantes del PUSC, otros que estaban desencantados de la política y querían un discurso estridente $y$ fantasioso como el que Guevara ofrecía. No obstante, como se vio, con el tiempo, una vez que se consideró que se estaba convirtiendo en una eventual amenaza por su crecimiento de intensión y simpatía de voto, los otros partidos (PLN, PUSC, PAC) comenzaron a atacarlo, denunciando prácticas inusuales de financiamiento, resaltando sus inconsistencias discursivas y destacando que su discurso actual era engañoso y ocultaba su pensamiento real.

En el caso del Pusc, el desenlace de la aventurada candidatura de Rafael Ángel Calderón F. terminó en el despeñadero ya que el Tribunal de juicio lo encontró culpable de los cargos y lo condenó a prisión. Razón por la cual Calderón renuncia a sus aparentes aspiraciones ${ }^{10}$ presidenciales. Ante el vacío que deja, él solicita a Fishman que asuma el compromiso, a sabiendas de que no tiene ninguna posibilidad de ganar; pero sí de evitar que el partido desaparezca $^{11}$.

Particularmente, el candidato Luis Fishman del PUSC, entendió que se debía descalificar a Guevara, ya que estaba llevándose a los ex del PUSC; esto hizo que fueran ataques duros y al cuerpo los que Fishman emprendió con buen suceso contra Otto; ya que logró atraer algunos votos para su candidatura,

10 Desde nuestra perspectiva, la candidatura de Calderón era más un juego hacia adentro de la dinámica del juicio, que un interés verdadero por asumir la candidatura a la presidencia. Él en el juicio trató de utilizar las fuerzas mediáticas y la publicidad para confundir o para presionar. Dada la sentencia, ya no tenía sentido para sus verdaderos intereses continuar como candidato.

11 En una entrevista en el Diario Extra de hace dos o tres años, indicaba que lo más probable era que el PUSC podría desaparecer. De hecho ha desaparecido como co gobierno. principalmente para diputados ${ }^{12}$; situación que debilitó al Movimiento Libertario.

Las otras personas candidatas jugaron distintos papeles, unos más tristes que otros, en tanto abdicaron de sus propias aspiraciones $y$ la de sus partidos; situación diferente al caso del rector Trejos, quien se mantuvo con fortaleza hasta el final; no logrando ninguna de sus aspiraciones, pero sí su convicción partidaria e idealista.

\section{III momento. El banderazo del tribunal} supremo de elecciones

Cuando se abre oficialmente el proceso electoral, este tenía más de año y medio de estar efectivamente $y$ de manera generalizada en campaña. De hecho, parte de los errores del PAC fue no posesionarse en la imagen del electorado $y$ parte de los logros del ML $y$ del PLN fue que se mantuvieron en la imagen de los y las electoras a través de una intensa presencia mediática desde "antes de la campaña".

Cuando el TSE da la salida, el PLN y el ML ya llevaban más de una vuelta de ventaja al PAC. Aparentemente, el Partido Acción Ciudadana creía que podía mantenerse al margen de la participación publicitaria mediática, ya que tenía acciones acumuladas en las dos elecciones anteriores y que en esta campaña las iba a concretar en la elección presidencial.

Nada más lejano de la realidad que pensar que se puede sumar pasado con presente sin despejar la ecuación de los cambios. En este sentido, se vio burocráticamente el derecho a ganar la presidencia de la República; pensamiento que solo era posible concebir, si no se atendía a estudios de campo sobre intención de votos; o bien si no se conocía realmente que buscaba y necesitaba la gente de la oferta política.

En alguna medida, el PAC pretendió un vuelo en un 747, abandonando los instrumentos digitales de navegación y dejando su orientación y conducción en manos de la supuesta experiencia del piloto. El resultado fue evidente, un aterrizaje forzoso con conse-

\footnotetext{
12 Es interesante indicar que Fishman tenía doble candidatura: para presidente y para diputado; donde finalmente fue electo.
} 
cuencias lamentables para las aspiraciones de gobierno del partido y de su principal dirigente: solo se obtuvo un $25 \%$ de la votación. Y esto porque algunas personas ex simpatizantes y ex dirigentes - ante el evidente "descalabro" que se avizoraba- emprendieron acciones independientes a favor del partido. Un elemento que detonó esta reacción fue la negativa de la banca pública de financiar al PAC con la compra de los bonos del estado - ya que las encuestas le daban un porcentaje inferior al $15 \%$ situación que motivó la acción de algunos simpatizantes de las elecciones pasadas a sumarse $y$ actuar pro PAC. Importancia menor en este repunte del PAC fue su alianza ${ }^{13}$ con Rolando Araya del emergente Partido Alianza Patriótica y Walter Muñoz del Partido Integración Nacional.

Por su parte Laura Chinchilla y el PLN asumieron una conducción del proceso electoral en el cual su meta era consolidar los votos logrados en las primarias $y$ atraer simpatizantes del pasado liberacionistas, que podían volver con una candidata acuerpada por el viejo sector liberacionista y el auto referido presidente Arias. Con la ganancia adicional de su condición objetiva de mujer, que aparecía a los ojos de las votantes potenciales como alguien "cercana", "sencilla" y portadora de la imagen de la mujer "media" costarricense en cuanto sus vínculos familiares, forma de vestir y hábitos religiosos ${ }^{14}$.

Esta condición subjetiva de mujer candidata a la presidencia le adicionaba algo que ningún otro candidato (con posibilidades rea-

13 Esta alianza fue tardía y además no generó una verdadera unión de fuerzas electorales, ya que ni Araya ni Muñoz tenían seguidores; mas la alianza facilitó una salida menos dramática para Rolando Araya que una acumulación de votos. Incluso el día de las elecciones la ciudadanía podía votar por las dos personas que se aliaron a Solís.

14 Con esta idea lo que queremos resaltar es que a pesar de la novedad de ser una candidata mujer, lo medular es que ese factor que podía generar distancia, rechazo o descalificación por parte de hombres y mujeres, no ocurrió de una manera sistemática; ya que predominaron otras cualidades o particularidades de la persona mujer con que ella (la candidata liberacionista) se presenta a las elecciones. les) tenía; nos referimos a la novedad; es decir, a pesar de que ella ya había estado dentro de la política e incluso haber sido vice presidenta del gobierno vigente, era diferente por la novedad misma de que era una mujer que aspiraba a la presidencia con posibilidades de ganar.

Para la oposición era muy incómoda la situación; ya que los principales candidatos no presentaban ninguna novedad e inclusive, en el caso de Ottón Solís, más bien aparecía como vieja figura y Otto Guevara como figura repetida $y$ repitente. A esto se debe adicionar, las limitaciones que tenían para abordar el tema de género y también generar críticas frontales a la candidata liberacionista; ya que se conocía el terrible resultado que tuvo para Johnny Araya cuando por medio de un tercero atacó ad hominem a la entonces pre candidata liberacionista. Esto por cuanto a la "gente" no le gusta que públicamente se ataque a una mujer en política ${ }^{15}$.

Esto dejaba con pocas armas de contra ataque a los opositores y permitió una gestión de campaña relativamente tranquila para quien posteriormente ganó las elecciones. No obstante, no significó que no intentaran descalificar su candidatura en los debates en los medios de comunicación; principalmente asociándola como incondicional del presidente Arias.

Esta oposición no pudo lograr descalificar a la candidata liberacionista con su asociación al llamado "continuismo" porque de una u otra forma sectores importantes de la sociedad habían llegado a la conclusión que el gobierno de los Arias no había sido tan "malo" ni incompetente como la oposición partidaria creía o quería hacer ver a la ciudadanía. De hecho - como lo indicó anteriormente- parte del triunfo de Laura Chinchilla en las primarias se debió en parte al apoyo abierto del presidente Arias. Y si bien en las elecciones presidenciales no podría ser la variable explicativa central del la victoria verde, sí es cierto que no percibir al gobierno como nefasto, incompetente o simplemente

15 Esto, independientemente de que en nuestra sociedad tengamos rasgos machistas y altos niveles de agresión psicológica y física contra las mujeres. No obstante existe un discurso anti agresión a las mujeres en la vida pública. 
lo que la gente llama "malo" jugó a favor de la continuidad del PLN en el gobierno. Y esto la oposición no lo entendió, ya que no logró apuntar a los verdaderos yerros del gobierno liberacionista. En síntesis, un gobierno débil de los Arias, no fue suficientemente explotado en la campaña política, ya sea por problemas de diseño publicitario o por desconocimiento del pensamiento de la gente.

\section{EL ROL DE LAS ENCUESTAS Y LOS SIGNOS DE LOS} DISCURSOS

Las encuestas siempre presentaron como una clara ganadora a la candidata liberacionista. En agosto de 2009, una encuesta de Borges $y$ asociados indicaba que Laura Chinchilla obtiene un 43\%, Otto Guevara un 9\% y Ottón Solís un $8,3 \%$; uno se preguntaba entonces ¿qué estarán pensando estos aspirantes a la presidencia? y ¿qué impacto puede tener sobre el diseño de la campaña política y el mismo electorado? (En el caso de Rafael Ángel obtuvo un 3,8\% y se suponía que estaba pensando más en una candidatura en función del resultado del juicio que en el proceso electoral).

Una primera derivación de la encuesta ${ }^{16}$ de opinión claramente perfila como posible ganadora a la candidata del PLN; esto luego sería una verdad política. Por otra parte, dicha encuesta también describía algo inesperado y dramático; un PAC que se encontraba por debajo de Guevara y en un porcentaje inferior a su último resultado electoral. Nótese que la diferencia con el PLN era de casi treinta $y$ cuatro puntos porcentuales $y$ eso era una diferencia insalvable sin un fenómeno extraordinario.

A esta encuesta se agregaron otras, en las cuales la perspectiva era parecida. A finales de 2009 sale a la luz una encuesta de CID Gallup en la cual Laura Chinchilla obtenía un $45 \%$, Otto Guevara un 23\%, Ottón Solís un $15 \%$ y Fishman un 11\%. En esta ocasión lo sorprendente fue el crecimiento descrito por el Movimiento Libertario, el cual a todas luces resultaba poco creíble que en menos de dos

16 La encuesta salió publicada en el Diario Extra de agosto. meses creciera tanto hasta llegar al 23\%; algo parecido en cuanto a credibilidad lo era el caso del Pusc, que según esta empresa tenía más de un $10 \%$, a pesar de estar recién lanzado como candidato, en cuanto al PAC, parecía acertado el $15 \%$. Estos resultados, con excepción de 45\% de Laura Chinchilla, no parecían entonces creíbles. Pero en todo caso, sí estaban dentro de las tendencias generales que las otras empresas encuestadoras planteaban.

En general, los resultados de las encuestas confirmaban la tendencia original de que la candidata del PLN llegaría a la presidencia; de lo que había duda era de quien quedaría en segundo lugar y cuál sería la diferencia. En particular, este segundo lugar era importante ya que de lograrlo el Movimiento Libertario, podría indicar una fuerte radicalización del pensamiento conservador en núcleos significativos de la sociedad costarricense. Pero solo el hecho de la duda de quien estaría de segundo, era una gran derrota para Solís y su partido.

La única encuesta que asumió una posición diferente muy "crítica" y de dudosa intensión fue la que en el último día en que se permitía publicar resultados, sacó la empresa encuestadora Imerca, inscrita ante el Tribunal Supremo de Elecciones (TSE) y vaticinó una segunda ronda electoral. Laura Chinchilla encabezaba con $35,2 \%$ de las intenciones de voto (recordemos que se requiere más del $40 \%$ para ganar la presidencia), seguida por Ottón Solís con 15,2\% y Otto Guevara con $14,8 \%$. La presentación vino acompañada de comentarios de Haydee Mendiola quien denunció manipulación en las encuestas. Asimismo, la directora de Imerca, Rosa Amelia Quirós, dijo que los medios de comunicación o las casas encuestadoras como Unimer, Borge y Asociados, o CID Gallup, hacían proyecciones solo tomando en cuenta a los que ya están decididos por quién votarán, y entonces eso eleva los márgenes de supuesta votación para los partidos, con lo que se ponía a ganar a Chinchilla con más del $40 \%$ de los votos, lo cual no refleja la realidad. A estas voces de crítica se les sumó el politólogo Jaime Ordoñez, quien dijo "existen manipulaciones" por lo que el resultado está inflado para todos los partidos, 
por lo que habrá segunda ronda ya que el PLN anda alrededor del 35\%, el PAC de un 15\% o $16 \%$ y el ML de un $14 \%$.

En general, parece que esta última encuesta fue un intento político de crear inseguridad y dar aliento a los que estaban por debajo para creer en un balotaje como salida a la incapacidad de ganar en primera ronda.

Así también, el resultado muestra que las encuestas no incidieron en las elecciones como en otras ocasiones y que evidenciaron que algunas pueden describir la realidad $y$ otras crear realidades. En lo que sí incidieron fue en las posibilidades del financiamiento de los partidos; en general en todos los partidos; aunque el caso más dramático fue el del PAC, que por el bajo porcentaje que obtenía en las encuestas, la banca estatal $-y$ muy probablemente la privada- no le financiaron su campaña. En este caso, parece que más bien le favoreció en muchos sentidos.

En cuanto a los temas centrales del discurso, encontramos un fenómeno interesante en la concentración del mismo, en el tema de seguridad; el cual fue direccionado por el Movimiento Libertario y su líder Guevara; a este le siguieron los otros partidos con poco o ningún éxito; ya que la temática se convirtió en la punta de lanza de una crítica al gobierno $y$ a los derechos de los indiciados, delincuentes y criminales. Mucho del discurso de seguridad se redujo a respuestas de fuerza en la cual cayeron todos los candidatos y candidatas; ya que para Guevara fue muy exitoso, a pesar de las "ocurrencias" que proponía, sin fundamento ni viabilidad histórico-jurídica en Costa Rica.

El discurso efectivista sobre seguridad opacó todas las otras problemáticas, incluyendo la del modelo económico y de sociedad; lo que de hecho agradó a la clase política que no quería retomar las tensiones del TLC y la alta conflictividad que se dio. Para cualquier analista hubiese sido de esperar que la discusión de fondo se diera sobre las secuelas de dicha confrontación; pero resulta que - aparentemente - a ningún contendiente $y$ partido, le era grato el tema: al PAC, por su pérdida de liderazgo en el proceso; al punto que una de sus candidaturas a la vicepresidencia de la
República era una de las líderes del "Sí al TLC"; como un mecanismo de neutralización de su pasada oposición; por su parte el PLN, evitaba discutir el tema ya que podía generarle inconveniencias $y$ acrecentar el sentido de la oposición en grupos que se habían dispersado después del Referéndum; $y$ por su parte el Movimiento Libertario no quería abanderar la discusión ya que en esa lucha jugaron un papel segundón y muy subordinado al PLN y a los Arias; algo similar ocurría con el PUSC.

Por lo antes dicho, la campaña no tocó elementos económico-sociales de relevancia; se escucharon propuestas tímidas e inconclusas en todos los campos sin la claridad de diseño ni de viabilidad. Hasta se habló de entregar una computadora a cada niño y niña, $y$ a los jóvenes de este país ${ }^{17}$, cuando sabemos que eso es un canto de sirenas o peor que eso. También sobre los menores de edad, se habló de la necesidad de crear redes de cuido pero sin ningún diseño previo. El tema del género tampoco fue tratado sistemáticamente y en medio de la campaña el PLN eligió a una de sus diputadas como defensora del pueblo, en un acto poco ético y provocador que no suscitó por parte de la oposición un discurso apropiado, por lo que al final fue inocuo el hecho político excretable; como también lo fue el caso de la ex legisladora guanacasteca que utilizaba las avionetas del Estado para su transporte personal. La corrupción fue un tema menos tratado que en la campaña anterior y a pesar de los actos de corrupción que se dieron en el gobierno, no fueron bien tratados políticamente por la oposición, por lo cual no impactó electoralmente.

Los debates que se efectuaron en radio, prensa y televisión fueron muchos, $y$ en todos o la mayoría de ellos, los contendientes de oposición no lograron avasallar políticamente a la candidata oficialista. Políticamente, fue muy extraño que aunque la diferencia de intensión de votos registrada indicaba la necesidad de una carga cerrada contra la candidata, los opositores no lograran desequilibrarla y más bien, en algunos debates, era la liberacionista quien

17 Esto lo planteó el candidato Guevara del Movimiento Libertario, sin explicar la fuente real de financiamiento... no la ilusoria. 
atacaba o respondía generando desbalances en sus oponentes.

Otro fenómeno interesante de los debates fue que conforme avanzó el proceso electoral, el más atacado fue Otto Guevara. En el caso del PLN, porque él les daba muy duro; el PAC porque deseaba el segundo lugar, y el PUSC porque quería recuperar los simpatizantes que se identificaban con Guevara. En fin, los debates permitieron conocer a los candidatos desde varias perspectivas, pero políticamente, el gran perdedor fue Guevara, ya que era otra persona en relación con el que salía en los anuncios publicitarios: aquel hombre seguro, propositivo, imbatible, lo convertían en un candidato dubitativo, débil y poco propositivo, cuando lo sacaban de su discurso televisivo. Por su parte, Solís se veía enconchado en el pasado y en una falsa superioridad de experiencia política que no encontraba sustento en la realidad -independientemente de sus buenas intensionesno logró llamar la atención del electorado con un discurso remozado y actual. Por otro lado, Fishman logró la mayor ventaja en los debates, ya que resultó "simpático" para los espectadores y eso le dio puntos al Partido. La candidata liberacionista no perdió en los debates y eso era en el fondo ganar, ya que de una u otra forma, se le observaba con una posición firme, muy similar a la de los anuncios, lo que le otorgaba credibilidad ante los suyos. Es decir, no desencantó a sus simpatizantes y eso era suficiente para ganar.

Los días previos a la elección no marcaron diferencias significativas en las dinámicas y discursos antes descritos; sin embargo, se deben resaltar dos fenómenos importantes; el primero, tiene que ver con el repunte del PAC, donde se apreció una especie de reconstitución del espíritu de lucha por el triunfo que no se le había observado a lo largo de la campaña y que se observaba en los centros urbanos principalmente ${ }^{18}$.

En cuanto al Movimiento Libertario, se observó el fenómeno de un Otto Guevara muy cuestionado por las fuentes de su financia-

18 La negativa del financiamiento por el Banco de Costa Rica generó un sentimiento de indignación que se manifestó en apoyar al PAC por sectores que estaban al margen de esta campaña. miento, las débiles respuestas en los debates y el desgaste propio de una campaña efectivista $y$ reiterada, que cuando las personas se preguntan más allá del "lema de cambio", se encontraban con un vacío sin respuestas concretas. Esto último generó una especie de revaloración de la simpatía o intensión de voto hacia el libertario Guevara; quien además se había visto afectado por el llamado del candidato Luis Fishman a los socialcristianos para que no apoyen a Guevara y se mantuviesen en el Pusc.

Por su parte, al final de la campaña el candidato del Frente Amplio se concentró más en sus aspiraciones de llegar al congreso, así como fortaleciendo la campaña de sus principales aspirantes a diputados(as).

\section{EL DÍA DE LAS ELECCIONES}

El día de las elecciones, se evidenció lo que algunos habíamos previsto, la organización funcional del PLN para poder captar en las urnas las intensiones de votos de sus simpatizantes y de algunos indecisos. El partido que había hecho su "ensayo" en las primarias; donde movilizaron casi quinientas mil personas, le había servido; no solo por la capacidad desarrollada de previo sino por la imagen de "máquina electoral aceitada" y sin fisuras. Gente de mucha experiencia en una gran cantidad de campañas anteriores habían regresado al partido $y$ con estas personas, otros $y$ otras, que vieron en el PLN un partido con organización para ganar y posiblemente asociado a ello, la capacidad para gobernar.

En las aceras del frente, o de al lado de atrás, se observó un Movimiento Libertario venido a menos y con poca capacidad organizativa que - según ellos - impidió recoger todos los votantes que decían las encuestas; si esto es o no cierto, no lo sabemos; pero lo que sí se evidenció fue el "desfallecimiento" de la dirigencia y su líder cuando vieron el desenlace de su aventura electoral.

Por su parte, como ya se indicó, el Partido Acción Ciudadana impresionó en los centros urbanos con movilizaciones espontáneas de sus simpatizantes, suponemos que algunas planeadas, pero que en su conjunto 
hacían creer en un repunte amenazante para el Partido Liberación Nacional. No obstante la impresión, lo cierto es que el resultado evidenció la falta de un partido con una "organización inteligente" que aprendiera de sus dos experiencias anteriores $y$ que atendiera las inteligencias de sus cuadros intermedios y en desarrollo. La organización, para el día 4 de febrero, no fue suficiente para atraer indecisos y toda persona que no estaba con el PLN y el gobierno.

IV momento. Algunos por qué de los resultados de las elecciones 2010

Concluido el proceso electoral, el análisis del mismo nos puede permitir entender mejor lo acontecido y lo que puede ocurrir en la próxima administración del gobierno liberacionista.

Un aspecto interesante que debemos reconocer en este proceso electoral es el peso de las elecciones primarias, el cual jugó un papel significativo en el resultado final.

Liberación Nacional logró capitalizar un número importante de simpatizantes de la candidata y además reposicionarse como un partido "grande", con capacidad organizativa y con fuerza política.

Contrariamente, el Partido Acción Ciudadana, no adquirió en sus primarias el apoyo de grandes sectores, con el agravante adicional de que en esta convención salió devaluado ante la opinión pública y algo fraccionado.

Otro factor determinante, fue el tipo de oposición que durante cuatro años hizo el PAC, que en alguna medida quedó atrapado en la discusión del TLC y no necesariamente fue bien visto ni por los que estaban a favor del proyecto ni por quienes tenían una posición "dura" contra él; situación que se agravó cuando en un afán de compensar el PAC incluye como candidata a la vice presidencia a una persona dirigente del "NO". A lo anterior, se le sumó el ingreso tardío a la campaña política publicitaria; lo que dejó un espacio para que Otto Guevara se apropiara de la idea del "Cambio" que en una u otra medida el PAC había atesorado en la anterior campaña. Así el PAC, se encontró cuesta arriba e inició con una intensión de voto muy por debajo del PLN e incluso del mismo Movimiento Libertario.
Por otro lado, el PUSC inició, tardíamente, su campaña pero con una idea de recuperar sus simpatizantes y para ello recurrió a una serie de mecanismos publicitarios que llamaron la atención, promoviendo una visión de su candidato Fishman como una persona de experiencia y confiable, que se hizo atractivo para quienes se habían marchado del Pusc y buscaron su regreso. Esto tiene un impacto negativo para Otto Guevara; a quien se le atacó directamente indicando a los socialcristianos que esa no es la persona que los puede representar.

En este escenario y con estos actores $y$ actrices, la comedia y el drama, según cada quien, concluye con una victoria clara de Laura Chinchilla y una derrota contundente del PAC. En el caso del PLN, su victoria es parcial, ya que no logró la mayoría en el Congreso e inclusive pierde alguna curul.

En cuanto al Movimiento Libertario, es evidente su derrota en relación con las expectativas; aunque obtienen cierto logro, en comparación con el resultado de hace cuatro años.

El Pusc sigue vivo y no desaparece, por lo que el resultado es positivo para este partido que obtuvo seis puestos en la Asamblea.

Por su parte, el PASE ingresa a otro nivel con cuatro diputados, que lo compromete a una gestión más fuerte en la Asamblea Legislativa. Por último, los partidos minoritarios tendrán, con un solo diputado, capacidad para negociar, ya que el partido de gobierno requiere de sus apoyos.

Las elecciones concluyeron, pero el proceso democrático continúa; debemos como ciudadanos y ciudadanas velar porque se concreten aquellas promesas de campaña que realmente nos beneficien y promuevan un desarrollo del país con sentido humano, equitativo y armónico con el ambiente. Debemos ser contralores(as) y gestores(as) de las decisiones más importantes; este es uno de los verdaderos sentidos de la democracia. El otro, es que participemos en conjunto de la toma de decisiones, aunque no seamos funcionarios de gobierno ni estemos en la Asamblea Legislativa; solo por el hecho de ser ciudadanos en una sociedad que debe tener más que una aspiración al ser democrático. 


\section{BIBLIOGRAFÍA}

Bauman, Zymunt. Tiempos líquidos. Vivir en una época de incertidumbre. México: Editorial Tusques Editores, 2009.

Bauman, Zymunt. La globalización consecuencias humanas. México: Fondo de Cultura Económica, 2004.

De Sousa Santos, Boaventura. Reinventar la democracia: reinventar el estado. Argentina: CLACSO, 2006.

Canfora, Luciano. Crítica de la retórica democrática. España: Editorial Crítica, 2003.

Chinchilla, José Carlos y Mora, Maynor Antonio. El sistema de partidos políticos en Costa Rica durante la segunda mitad del siglo XX. Costa Rica: Editorial UCR, 2005.

Chinchilla, José Carlos y Carranza, Carlos. "Ajuste estructural en Costa Rica: 19851993". En: Los pequeños países de América Latina en la hora neoliberal. Venezuela: Nueva Sociedad, 1994.

Chinchilla, José Carlos. "Corrupción y democracia en Costa Rica". Congreso Latinoamericano de Sociología. México: ALAS, 2007.

Carbonell, Miguel. Poder, derecho y corrupción. México: Editorial Siglo XXI, 2003.

Dahl, Robert. La democracia: una guía para los ciudadanos. Argentina: Editorial Taurus, 1999.
Dahrendorf, Ralf. En busca de un nuevo orden. España: Ediciones Paidós Ibérica SA, 2005.

Guéhenno, Jean-Marie. El fin de la democracia: la crisis politica y las nuevas reglas del juego. España: Ediciones Paidós Ibérica SA, 1995.

Guéhenno, Jean-Marie. El porvenir de la libertad: la democracia en la era de la globalización. España: Ediciones Paidós Ibérica, SA, 2000.

Elliott, Kimberly Ann. La corrupción en la economía global. México: Editorial Limusa SA, 2001.

García, Rolando. Sistemas complejos. Argentina: Editorial Gedisa, 2007.

Hengstenberg, Peter; Kohut, Karl; Maihold, Gunther. Sociedad civil en América Latina: representación de intereses $y$ gobernabilidad. Venezuela: Editorial Nueva Sociedad, 1999.

Mallen, Jorge F. La corrupción aspectos éticos, económicos, políticos y jurídicos. España: Editorial Gedisa, 2002.

Quesada, Fernando. Sendas de democracia. España: Editorial Trotta, 2008.

Touraine, Alain. Un nuevo paradigma: para comprender el mundo de hoy. España: Ediciones Paidós Ibérica SA, 2005.

Fecha de ingreso: 23/11/2010 Fecha de aprobación: 25/04/2011 